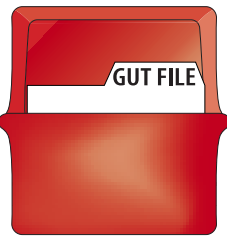

\title{
Cholangiocarcinoma arising after biliary-enteric drainage procedures for benign disease
}

\section{BACKGROUND}

Although choledochoduodenostomy was widely performed for choledocholithiasis in the 1960s and 1970s, Roux-en-Y hepaticojejunostomy is currently the preferred biliary-enteric anastomosis for benign and malignant disease and is generally considered a low risk procedure, aside from the potential for cholangitis.

\section{AIMS}

We report three cases referred over a 12 month period in which cholangiocarcinoma developed after previous biliaryenteric anastomosis, and review the literature to determine the likelihood of an association.

\section{PATIENTS}

\section{Case No 1}

A 51 year old female developed obstructive jaundice 26 years after choledochoduodenostomy for a biliary stricture after iatrogenic bile duct injury. Endoscopic retrograde cholangiopancreatography (ERCP) showed neoplastic infiltration at the level of the anastomosis, biopsy of which revealed cholangiocarcinoma (fig l). Percutaneous transhepatic cholangiography (PTC) demonstrated diffuse biliary strictures and biliary endoprostheses were inserted. Death occurred two months later.

\section{Case No 2}

A 73 year old female presented with obstructive jaundice 39 years after

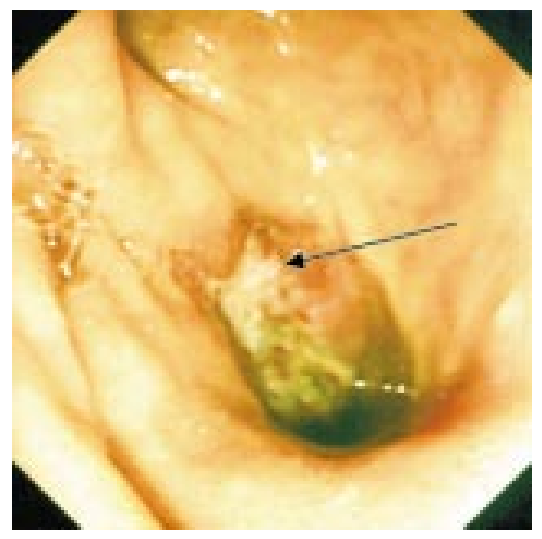

Figure 1 Adenocarcinoma (arrow) on the biliary side of a choledochoduodenal anastomosis, as seen at endoscopic retrograde cholangiopancreatography. biliary-enteric anastomosis for iatrogenic bile duct injury. Computed tomography scanning and PTC revealed cirrhosis and focal strictures of the biliary confluence and common bile duct, which were stented. The patient died two weeks later. Autopsy confirmed cirrhosis and multifocal cholangiocarcinoma.

\section{Case No 3}

A 72 year old male renal allograft recipient developed obstructive jaundice 15 years after choledochoduodenostomy for choledocholithiasis. ERCP and PTC demonstrated hilar stenosis and biopsy confirmed cholangiocarcinoma. A palliative surgical bypass was undertaken. The patient died four months after diagnosis.

\section{DISCUSSION}

The occurrence of cholangiocarcinoma many years following surgical biliaryenteric bypass may be coincidental but it raises the possibility of an aetiological link. An alarming incidence of cholangiocarcinoma among a cohort 1003 patients has recently been reported, ${ }^{1}$ while another study reported a $7.4 \%$ incidence of cholangiocarcinoma after sphinctero - plasty. ${ }^{2}$ Twelve other cases of cholangiocarcinoma occurring late (average 20 years) after biliary-enteric drainage have also been reported..$^{3-9}$ Mean survival was 3.3 months. This dismal outcome may be due to the multifocal nature of the tumours, supporting the hypothesis of toxic carcinogenesis affecting the biliary epithelium, causing a field change.

As for choledochal cysts where there is an abnormal pancreaticocholedochal junction, an activated mixture of pancreatic secretions and bile may contain cytotoxic components, and may result in chronic inflammation. ${ }^{10} 11$ Bacterial infection is a further factor contributing to the chronic irritation of the mucosa. All three patients in this report demonstrated the known association between choledochoduodenostomy and cholan -gitis. ${ }^{12}$ This strong relationship is supported in two previous reports. ${ }^{12} \mathrm{Mu}$ cosal changes have been documented in humans late after choledochoduo -denostomy, ${ }^{13}$ and in two animal models biliary drainage procedures have induced premalignant or malignant changes to the biliary epithelium. ${ }^{14}{ }^{15}$
It remains to be verified whether the recent epidemiological data which have shown a steady increase in the incidence of cholangiocarcinoma in England and Wales since the early $1980 \mathrm{~s}^{16}$ corresponds to the popularity of choledochoduodenostomy two decades previously.

\section{CONCLUSION}

Experimental, clinical, and epidemiological data are available to support the hypothesis of a link between cholangiocarcinoma and biliary drainage procedures. We believe that the evidence is strong enough to prompt a reappraisal of policies regarding these procedures.

V Bettschart, R A E Clayton, R W Parks, O J Garden, Department of Clinical and Surgical Sciences (Surgery), University of Edinburgh and Scottish Liver Transplant Unit, Royal Infirmary of Edinburgh, Edinburgh, UK

C O C Bellamy, Department of Pathology, University of Edinburgh and Scottish Liver Transplant Unit, Royal Infirmary
of Edinburgh, Edinburgh, UK

Correspondence to: $\mathrm{V}$ Bettschart, Department Surgery, University Of Edinburgh, Royal Infirmary of Edinburgh, Lauriston Place, Edinburgh EH3 9YW, UK V.Bettschart@ed.ac.uk

\section{ACKNOWLEDGEMENT}

V Bettschart was supported by the "Sicpa Foundation" and the "Fondation du $450^{\text {ime }}$ Anniversaire de l'Université de Lausanne".

\section{REFERENCES}

1 Tocchi A, Mazzoni G, Liotta G, et al. Late development of bile duct cancer in patients who had biliary-enteric drainage for benign disease: a follow-up study of more than 1,000 patients. Ann Surg 2001;234:210-14.

2 Hakamada K, Sasaki M, Endoh $M$, et al. Late development of bile duct cancer after sphincteroplasty: a ten- to twenty-two-year follow-up study. Surgery 1997; 121:488-92.

3 Shields HM. Occurrence of an adenocarcinoma at the choledochoenteric anastomosis 14 years after pancreatoduodenectomy for benign disease. Gastroenterology 1977;72:322-4.

4 Haratake J, Horie A, Takeda N. (Cancer of the intra-pancreatic common bile duct observed 9 years after choledochojejunostomy). Gan No Rinsho 1983;29: 1367-70

5 Leborgne J, Heloury Y, Lavignolle A, et al. (Cancer of the bile ducts above the anastomosis following choledocoduodenal anastomosis for common bile duct lithiasis. 2 cases). Ann Chir 1984;38:369-73.

6 Herba MJ, Casola G, Bret PM, et al Cholangiocarcinoma as a late complication of choledochoenteric anastomoses. AJR Am J Roentgenol 1986;147:513-15. 
7 Perez RL, Gabarrell OA, Vinas SJ, et al. (Biliary tract cancer following bilioenteric anastomosis). Rev Esp Enferm Dig 1994;86:853-5

8 Schumacher G, Bechstein WO, Kling $N$, et al. (Bile duct carcinoma in an adenoma in the anastomotic area after hepaticojejunostomya case report). Z Gastroenterol 1997;35:1081-6.

9 Strong RW. Late bile duct cancer complicating biliary-enteric anastomosis for benign disease. Am J Surg 1999;177:472-4.

10 Kobayashi S, Asano T, Yamasaki M, et al. Risk of bile duct carcinogenesis after excision of extrahepatic bile ducts in pancreaticobiliary maljunction. Surgery 1999; 126:939-44.
11 Shimada K, Yanagisawa J, Nakayama F. Increased lysophosphatidylcholine and pancreatic enzyme content in bile of patients with anomalous pancreaticobiliary ductal junction. Hepatology 1991;13:438-44.

12 Madden JL, Chun JY, Kandalaft S, et al. Choledochoduodenostomy: an unjustly maligned surgical procedure? Am J Surg 1970;119:45-54

13 Eleftheriadis E, Tzioufa V, Kotzampassi K, et al. Common bile-duct mucosa in

choledochoduodenostomy patients histological and histochemical study. HPB Surg 1988;1:15-20.

14 Kurumado $\mathrm{K}$ Nagai $\mathrm{T}$, Kondo $\mathrm{Y}$, et al . Long-term observations on morphological changes of choledochal epithelium after choledochoenterostomy in rats. Dig Dis Sci 1994;39:809-20.

15 Tajima Y, Eto T, Tsunoda T, et al. Induction of extrahepatic biliary carcinoma by $\mathrm{N}$-nitrosobis(2-oxopropyl)amine in hamsters given cholecystoduodenostomy with dissection of the common duct. Jpn J Cancer Res 1994;85:780-8.

16 Taylor-Robinson SD, Toledano MB, Arora S et al. Increase in mortality rates from intrahepatic cholangiocarcinoma in England and Wales 1968-1998. Gut $2001 ; 48: 816-20$

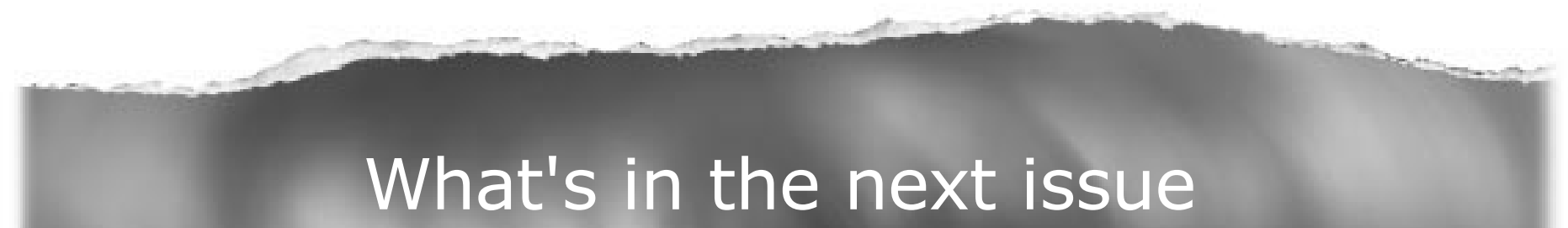

Future content

See which articles have just been accepted for publication and preview the table of contents for the next issue a month before it is published

www.gutjnl.com 